\title{
Teacher Training and Its Impact on Novice Teachers' Performance in the EFL Classroom
}

\author{
Fatma Zohra Zemouchi \\ University of Algiers 2, Algeria \\ f.zohra.zemouchi@univ-alg2.dz
}

\section{ABSTRACT}

\begin{abstract}
The main purpose of the present study is to look into the teacher training offered by a private language centre in Sidi Yahia (Algiers, Algeria) to novice teachers and to explore whether these teachers later on make use of and reflect on the teaching skills taught throughout the course of their training. Consequently, a case study of five novice teachers of English has been conducted during a period of two months. In an attempt to answer the three research questions posed by this investigation, three data collection tools have been utilized: document analysis, lesson observations (three for every participant) and one questionnaire for teachers. The collected data have been analyzed both quantitatively (closedended items) and qualitatively (open-ended items). The main results have shown that the language center training for teachers is rather conservative and focuses exclusively on the use of the direct method and the PPP approach. The study has also revealed that $80 \%$ of the teachers do not completely agree with the idea of using one method for all learners and have highlighted the importance of eclectic teaching. Therefore, they do not always stick to the approach that they have been introduced to during the course of their training and their classroom teaching performance progress is quite unstable. Although the school usually follows up on their progress and encourages them to reflect on their own teaching to improve, these novice teachers still feel trapped and unable to innovate within their classrooms.
\end{abstract}

Keywords: case study, direct method, eclectic teaching, PPP approach, reflective teaching

Cite this article as: Zemouchi, F. Z. (2021). Teacher Training and Its Impact on Novice Teachers' Performance in the EFL Classroom. International Journal of Higher Education Pedagogies, 2(2), 26-37. https://doi.org/10.33422/ijhep.v2i2.24

\section{Introduction}

Facing a language class full of learners from all walks of life while being inexperienced in teaching itself could be as complex as it sounds. That is why some researchers have shown great interest in teacher education and development in order to equip novice teachers with some basic teaching skills, help them survive their first year at work and encourage them to thrive in the future in order to establish some good-quality teaching.

\section{Literature Review}

In the 1990's, researchers started to show interest in the field of ESL/EFL teacher education and development thanks to Richards and Nunan who dealt with matters such as conceptual basis of program designs, the practicum and models of supervision, observations of teaching, reflective teaching, and action research (Tsui, 2011).

Wallace, in 1991, worked on how teachers had been trained and suggested three models of professional education: the craft model, the applied-science model and the reflective model.

(C) The Author(s). 2021 Open Access. This article is distributed under the terms of the Creative Commons Attribution 4.0 International License, which permits unrestricted use, distribution, and redistribution in any medium, provided that the original author(s) and source are credited. 
However, in 2016, Freeman mainly focused on the isomorphic relationship between language teacher education and general language education, in which he tried to explain the complexity of 'teaching teaching' and 'learning teaching' through the use of two views: a pronominal one and nominal one.

While both Wallace (1991) and Freeman (2016) focused on the theoretical aspect of teaching teachers, Richards (1996), Scrivener (2011) and other scholars emphasized the practical side. They all discussed how both novice teachers and experienced teachers, including their cognition, beliefs and knowledge, can improve and progress thanks to some suggested practical tips and the importance of reflective teaching.

All in all, the above-mentioned studies seem to agree that it is quite important to train novice teachers and follow their progress. However, there are no hints about whether these inexperienced teachers really apply what they are taught during their training course and whether they really reflect on their own teaching in the classroom after the training.

\section{Methodology}

To conduct this case study, a group of five novice language teachers of English, who were hired by the Sidi Yahia private language centre in 2017, were randomly selected. As a result, the research method used for collecting data was mixed; i.e. both quantitative and qualitative. In addition, three data collection tools were used to achieve the objectives of this study:

- The first one was a thorough analysis of documents related to the Instructor Qualification Program (IQP) in order to identify its content and objectives.

- The second one was the use of three structured lesson observations for each of the five novice teachers in order to find out how they would act in their classrooms, check whether they would make use of what they had been taught and how they would progress after being trained.

- The third tool was a teacher's questionnaire which was administered to all five novice teachers in order to collect more information about them and understand better their behaviour in the classroom.

Due to the nature of the data collected, two techniques have been used: the quantitative data (used for the questionnaire and lesson observations) was treated in accordance with descriptive statistics, while the qualitative data was examined with the help of content analysis.

\section{Results Description}

\subsection{Analysis of the Instructor Qualification Program}

The Instructor Qualification Program (IQP) is a comprehensive pre-employment training course which provides language teachers with the necessary skills in order to deliver quality lessons (all levels). The successful completion of this program usually guarantees these teachers' employment.

The IQP makes use of blended learning, i.e., trainees are asked to complete the online selfstudy packs as well as the face-to-face training at the language centre. However, both programs rely mainly on the Five Teaching Principles of the language centre: 
- Goal oriented instruction

- Maximized student participation

- Exclusive use of the target language

- Students learn through speaking \& listening, supported by reading \& writing.

- Grammar as a means of communication

To sum up, novice teachers go through two kinds of training programs: an online one and a live/face-to-face one.

\section{The Online Training (E-Learning Content)}

The Online program is mandatory and contains a number of self-study packs which are crucial to the effective delivery of quality lessons in the classroom later on. These self-study packs often include instruction, videos of real classes (of one, two or three students maximum), handouts (PDFs), quizzes and other resources which demonstrate and promote the use of the language centre method and techniques. Among the key modules that are available on the website, the trainees are advised to start with the following ones:

- Setting Learner Centered Goals

- Presentation Techniques

- Correction Techniques

- Practice Activities

- Fluency Activities

- Listening and Reading Activities

- Signposting and Wrap Up

All the above-mentioned modules demonstrate and teach what a quality lesson is like from its opening to its closing.

\section{The Live/Face-to-Face Training at the Language Centre}

The live training at the centre is intensive and usually takes about four to six days. It covers four modules and so each day has its own objectives. For the schedule, the day starts at 10 a.m. and finishes at 4.30 p.m. The trainees have two short coffee breaks of fifteen minutes: one around $11.15 \mathrm{a} . \mathrm{m}$. and the other one around $3.15 \mathrm{p} . \mathrm{m}$. and they have a longer lunch break of one hour at around 1 p.m.

The live training includes four essential modules which complement the ones previously completed online and it also helps the trainees put into practice what they have already learned from the online training.

By the end of the training, the trainees will have to prepare and deliver a lesson to their fellow trainees, who are asked to play the role of English learners, in order to demonstrate their understanding of the method, approach and techniques taught during the course of the training. The trainees who meet the language centre expectations are automatically hired and that phase marks the end of the whole training.

\subsection{Analysis of the Three Lesson Observations}

In this study, five newly-hired teachers were observed three times each in a period of approximately two months. Based on the five principles of the language centre and a sample of the detailed lesson observation used by the centre, a lesson observation grid was designed (see appendices: Tables $1-6$ ) to serve the purpose of this study. 


\section{- Lesson Observation One}

Table 1 shows that all five teachers have clearly set a goal for their lessons. However, some of them are still struggling with the lesson opening, the direct method (Presentation, Practice $\&$ Performance) and the lesson wrap-up.

Table 2 shows that some improvement is needed in terms of group handling as well as learning environment and STT (Student Talk Time). However, all teachers have met expectations in the other categories.

\section{- Lesson Observation Two}

Table 3 shows good mastery of practice and good improvement in terms of opening the lesson. It also draws attention to the increasing need for improvement in the other categories, especially presentation and performance.

The results in Table 4 show excellent command of STT, Group handling and the exclusive use of the Target language in the classroom by all five teachers. Nevertheless, the other categories still need to be improved.

\section{- Lesson Observation Three}

Table 5 shows massive improvement in terms of Lesson opening, goal setting and postperformance. However, the PPP approach and the Lesson wrap-up still need some work.

The information in Table 6 draws attention to the good mastery of correction techniques, STT, group handling and the use of the target language. However, some improvement is needed in the other categories, especially in the category of learning environment.

\subsection{The Analysis of the Teachers' Questionnaires}

The teachers' questionnaire was divided into three different sections. Each section served a specific purpose:

\section{- Section 1}

This section was designed to gather information regarding the participants' experience in teaching, if they had any.

The analysis of this section revealed that the five participants were in their early to midtwenties. They graduated from the university with a BA in English. They were teaching at the language centre for almost 8 months. The five participants had no experience in teaching the English language to adults before joining the centre. They just had some theoretical knowledge regarding teaching ESL/EFL thanks to their university education. However, none of them had the opportunity to put their knowledge into practice until they started teaching at the centre.

Finally, the data collected from Section 1 stated clearly that teaching at the center was the five participants' very first experience in teaching inside a real classroom with real ESL/EFL students.

\section{- Section 2}

This section was devoted to the training itself. It allowed the five participants to express themselves regarding its content.

The data collected from this section showed that all of the five participants completed the online and the live training between July and August 2017; however, they had different opinions concerning how beneficial it was to them. 
For example, only $40 \%$ of the participants strongly agree that the online training and the live training practice helped them implement the direct method in the classroom. They explained that by referring to the useful approach and techniques that the training introduced them to. However, the other $60 \%$ was shared among those who simply agreed $(20 \%)$ o and those who somewhat agreed (40\%). Their argument was that they were taught how to implement the direct method and the PPP approach within a small class of 2 or 3 learners, while a real class at the centre can include up to 12 or more. One of the participants had even compared the implementation of the method, its approach and techniques within such large classes to a "myth".

When the participants were asked what the centre does to guarantee the implementation of the method within their classrooms, their answers revealed five categories: formal lesson observations; students' feedback (surveys); re-doing the live training and re-delivering a lesson (a demo lesson).

In order to improve the implementation of the direct method and its approach in the classroom, the five participants suggested: encouraging informal peer observations, having extra training courses, including eclectic teaching and allowing teachers the freedom to be more creative.

All in all, the information gathered from Section 2 was quite pertinent and expressive.

\section{- Section 3}

This section concentrated on reflective teaching and the procedures the five participants use to reflect on their teaching practices.

Data showed that $80 \%$ of the participants reflect on their teaching practices using mainly peer observations followed by formal lesson Observations and audio \& video recording. While the least used procedures were: teaching journals, lesson reports, surveys \& questionnaires.

The data also revealed that the participants stayed updated on the latest teaching methods and techniques thanks to social media/internet, university courses, articles/books, seminars/webinars/conferences, and peer consultation.

In order to progress more as teachers of English, they recommended that the language centre encourage the use of ICTs within the classroom such as adding a computer with internet access in the classrooms and the teachers' room, introduce teachers to psycho-pedagogy to better manage their classes, give teachers some freedom to adapt their lessons to their learners' needs (inductive/deductive approach when necessary), create a platform for teachers to liaise with other teachers from similar language centres around the country, have an ongoing updated teacher training program that includes modern teaching skills, and encourage continuous learning for teachers. They also suggested updating the textbooks and classroom activities to beat students' boredom.

The data collected from this section showed clearly how aware the five participants were of their professional development.

\section{Results Discussion}

\subsection{The Language Centre Training for Instructors}

\section{RQ1: What kind of teacher training does the language centre offer to novice teachers?}

The language centre provides its instructors with two types of teacher education programs. In other words, pre-service teacher education often referred to as PRESET and in-service education usually shortened as INSET. In terms of content, some substantial effort was put into maintaining the balance between what was taught in theory (online training) and what 
was acquired in practice (live training). This led to the creation of a kind of blended learning which seemed to have facilitated the trainers' understanding of the language centre teaching standards and concepts and helped them draw a linking bridge between the theoretical phase and the practical one.

\subsection{The Implementation of the Direct Method and the PPP Approach}

\section{RQ2: Do novice teachers implement the teaching practices taught during the training?}

The review of the literature briefly illustrated how complex teacher education is; i.e. moving from the position of a student learning about teaching methods and skills to the position of a newly-qualified language teacher teaching and using what he/she has practiced during his/her introductory training (Freeman, 2016). Therefore, the second question which the present study attempted to answer was whether the newly-qualified instructors implement the direct method and the PPP approach in their classroom.

Thanks to the data collected by means of the three lesson observations performed over a period of time, some evidence regarding the implementation of the method in the classroom seems to be clear and visible. However, it can also be described as a little unstable, especially the application of the PPP approach. For example, while the application of the PPP approach was quite acceptable in Lesson Observation 1, it suddenly dropped in Lesson Observation 2. Then, it tried to gain a better status in Lesson Observation 3. Some of the reasons behind this unstable progress may be linked to the instructors' lack of experience or the fact that only $40 \%$ of them somewhat did approve of the exclusive use of the direct method.

The instructors, who participated in this study, discussed some issues that prevented them from using the direct method in the classroom such as the difficulty of incorporating it in one's way of teaching at first and the difference between the size of audience taught during the training and the one taught after the training (larger). This latter may be considered as a weakness in their training program. Moreover, the results showed that one of the five teachers did not completely agree with the method "for the reason that it's not tailored to fit all types of learners such as those with upper-intermediate to advance levels", while another one linked the difficulty of implementing that method in the classroom to the learners themselves, who were used to being taught deductively before and are not yet quite willing to step out of their comfort zone and learn inductively. In other words, a lot of these learners are not at all familiar with the exclusive use of the PPP communicative approach. As a result, the newlyhired teachers may find themselves spending a considerable amount of time on demonstrating, modelling and convincing -sometimes forcing- their students to adhere to that approach in order not to fall behind schedule.

According to the evidence mentioned above, some of the five teachers may not be following the direct method to the letter in their respective classrooms and that is possibly due to their need for more future practice, their personal beliefs regarding the method itself, their students' beliefs regarding the method and/or the change in the size of class taught after the training (large classes of 12 learners or more) comparing to the one taught during the training (small classes of 1 or 3 learners).

\subsection{Reflective Teaching}

RQ3: Do novice teachers reflect on their teaching practices after completing the training? In the literature, Scrivener (2011) believes that what makes a teacher a better one is first and foremost his/her current practice and then how open he/she is to future possible change. 
The main purpose behind including Section 3 in the teachers' questionnaire was to provide some possible answers to the third research question. Therefore, the data collected show that $80 \%$ of the newly-qualified instructors often reflect on their teaching practices mainly through:

- Peer observations which usually offer them the opportunity to attend some of the classes of their more experienced colleagues.

- Formal lesson observations which are often held by the Language Manager of Instruction who has previously been in charge of training them.

- Personal audio and video recordings which allow them to revisit their classes and help them identify what they should work on to improve as instructors at the language centre.

- Teaching journals, surveys and questionnaires were the least voted procedures.

Due to the fact that the language centre training basically revolves around the use of one unique method of teaching, the instructors have been asked about how they keep themselves updated on the latest teaching methods and techniques. Their answers revealed the following:

- Reading articles and books related to teaching and professional development topped the list as the instructors' most favourable way of staying up to date with what is happening in the teaching field

- Social media, including specialized Facebook pages and YouTube lecturing videos about teaching and pedagogical matters, were also considered very important by the newlyqualified instructors.

- Peer consultation was also suggested in order to become more familiar with some practices and to improve one's teaching skills.

- Presentations at the National Superior School of Teachers (ENS) were mentioned by a newly-qualified instructor in order to highlight their usefulness with regard to staying updated on the new teaching methods.

- Seminars, webinars \& conferences were added to the list due to their positive input and beneficial contribution in bringing together several teachers and educators and encouraging them to discuss the current/new trends in the educational field and to share their experiences with one another.

The newly-qualified instructors' suggestions and comments on how they keep up with the latest trends in teaching and education showed their awareness regarding the importance of continuous learning for teachers and also demonstrated their willingness to put some personal effort into becoming better language teachers in the future.

\section{Pedagogical Implications}

Thanks to these research findings, a set of recommendations was put forward in an attempt to draw the school's attention to a number of somewhat significant details regarding the training of newly-qualified/ novice teachers and to help create a more suitable atmosphere for them:

\section{- Continuity in Training}

After completing the initial training program, novice teachers may still lack some confidence in front of a real large classroom full of language learners. This could be the reason behind their persistence in asking for extra training courses and programs.

- Psycho-Pedagogy

According to the participants in this research, being a fluent speaker of the English language does not necessarily guarantee quality teaching or facilitates classroom management. 
Consequently, the newly-hired instructors' and the enrolled learners' psychological profiles should be studied carefully. In addition, the language centre could probably include some psycho-pedagogical courses in the training to draw the instructors' attention to the importance of this matter and raise their awareness concerning how to deal with different learner profiles in the classroom.

\section{- Freedom \& Creativity}

Due to the fact that the language centre insists on the unique and exclusive use of one method of teaching, which may not necessarily be suitable for all learners' profiles and learning styles, some instructors feel trapped and unable to innovate whenever they are faced with a new situation that urges them to think outside the box. Although they could probably think of a considerable number of creative alternatives which may help them move forward, they usually prefer to refrain from doing so. Unfortunately, this is not due to their lack of confidence but it is caused by their fear of not being approved of.

In her 2014 article: Where do we go from here? Method and Pedagogy in Language Learning, Penny Ur stated clearly that 'the principles guiding teachers in selecting procedures should not be dictated by any particular method recommended by researchers or theoreticians' and she added that 'teachers should be released from the pressure to use any particular method in their classrooms.' Instead, they should first be introduced to a variety of methods and types of procedures during their training programs and should also be given some time to grasp and reflect on them. Then, '[they] should have the right to make their own choices' as practitioners; however, there should be a clear rationale behind their decisions.

As a result, the language centre needs to reflect on granting their teachers some freedom to help them meet their learners' needs and to also take into account the inevitability of including a variety of new teaching trends in their classrooms in the near future.

\section{- ICTs Integration}

With the continuous and rapid development in the field of Information and Communication Technologies (ICTs), most people have become attached to their computers and cell phones. That is why Sidi Yahia language centre should not entirely rely on printed textbooks; on the contrary, it should rely on the future implementation of video lesson support and e-learning for both teachers and learners. This may turn their teaching and learning into more interesting and fruitful experiences, for both teachers and learners.

\section{- Liaison Between Language Centres}

In the last years, the ESL/EFL field has gained a lot of attention in Algeria and a simple click on Google using the right key words will display a long list of private language schools/centres all over the country. This significant data encouraged the suggestion of having a kind of exchange program which can allow teachers from different provinces in the country to meet and share their experiences. This idea may be achieved through organizing conferences/conference calls with other language schools/centres, or through selecting some of the most hardworking teachers in order to make them benefit from further training within the country/abroad.

\section{- Textbooks \& Classroom Activities Updating}

As innovating while exclusively using one teaching method is quite limiting and frustrating, some of the participants in this study would like the language centre to intervene in order to update the textbooks used and include some more engaging and motivating classroom activities such as educational games and learning through drama or theatrical plays. This idea 
may motivate learners and boost their confidence. Moreover, it can create a very positive atmosphere inside the classroom and reduce anxiety, as it can facilitate the development of a good rapport between the members of the class.

- Peer Observations

A peer observation is when a teacher attends one of his/her colleague's classes in order to gain more experience or simply to share some of their concerns. Lockhart and Richards (1996) state that self-inquiry plays an important role in learning about the field of teaching. Therefore, attending other colleagues' classes may help with the gathering of some valuable data. That is why Sidi Yahia language centre should advise its language instructors and encourage them to attend each other's classes more often in the future.

\section{Conclusion}

The main purpose of this research work was to explore the teacher training offered by Sidi Yahia language centre and to find out whether novice teachers implemented and reflected on what they had been instructed throughout their training course.

Thanks to the interpretations, the findings of this study revealed that the teacher training seemed quite conservative and promoted the exclusive use of one teaching method. Some of the five trained teachers did not totally approve of the concept of having one method of teaching for all learners; however, they reflected on it and applied it to some extent in their classrooms even though their performance did not always meet the language centre's expectations. This study also revealed that these novice teachers would have wished to be able to innovate within their classrooms, but the exclusive use of one method seems to be the obstacle because it limits their choices and creativity.

Therefore, this paper has put forward some recommendations and pedagogical implications related to future extra training, the implementation of the appropriate teaching methods in the classroom and the future inclusion of new teaching trends such as a language pedagogy as suggested by Penney Ur (2014).

\section{References}

Bell, J. (2010). Doing your research: A guide for first-time researchers in education, health and social studies (5th ed.). New York, NY: Open University Press.

Cohen, L., Manion, L., \& Morrison, K. (2007). Research methods in education (6th ed.). New York, NY: Routledge.

Creswell, J.W., \& Planco Clark, V. L. (2015). Understanding research: A consumer's guide (2nd ed.). Boston, MA: Pearson Education.

Dewey, J. (1910). How we think. Boston, MA: D. C . Heath \& Co.

Dewey, J. (1933). How we think: A restatement of the relation of reflective thinking to the educative process. Lexington, MA: D.C. HEATH AND COMPANY.

Fink, A. (2003). How to sample in surveys (2nd ed.). Thousand Oaks, CA: SAGE .

Freeman, D. (2016). Educating second language teachers: The same things done differently. Oxford, England: Oxford University Press.

Grady, M. P. (1998). Qualitative and action research: A practitioner handbook. Bloomington, IN: Phi Delta Kappa Educational Foundation. 
Grenfell, M. (1998). Training teachers in practice. Clevedon, UK: Multilingual Matters.

Lockhart, C., \& Richards, J. C. (1996). Reflective teaching in second language classrooms. New York, NY: Cambridge University Press.

Loughram, J. (2005). Developing reflective practice: Learning about teaching and learning modeling. London, England: Taylor \& Francis.

Matsuda, A. (2012). Introduction: teaching English as an international language. In A. Matsuda (Ed.), Principles and practices of teaching English as an international language (pp. 1-11). Bristol, UK: Multilingual Matters.

Max, C. (2010). Learning-for-teaching across educational boundaries. In V. Ellis, A. Edwards, \& P. Smagorinsky (Eds.), Cultural-historical perspectives on teacher education and development: learning teaching (pp. 212-237). New York, NY: Routledge.

Nunan, D. (1992). Research methods in language learning. New York, NY: Cambridge University Press.

Oppenheim, A. (1992). Questionnaire design, interviewing and attitude measurement (New ed.). New York, NY: Continuum.

Richards, J. C., \& Schmidt, R. (2010). Longman dictionary of language teaching and applied linguistics (4th ed.). London, England: Pearson Education.

Schön, D. A. (1983). The reflective practitioner: How professionals think in action. USA: Basic Books.

Scrivener, J. (2011). Learning teaching: The essential guide to English language teaching. London, England: Macmillan.

Tsui, A. B. (2011). Teacher Education and Teacher Development. In E. Hinkel (Ed.), Handbook of research in second language teaching and learning (Vol. II, pp. 21 - 39). New York and London: Routledge.

Ur, P. (1997, October). Teacher training and teacher development. The language teacher, 21(10), pp. 1-5.

Ur, P. (2014). Where do we go from here? Method and pedagogy in language teaching. ExELL, 2(1), 3-11.

Wallace, M. J. (1991). Training foreign language teachers: A reflective approach. Cambridge, England: Cambridge University Press.

Yin, R. K. (2009). Case study research: Design and methods (4th ed., Vol. 5). Thousand Oaks, CA: SAGE. 


\section{Appendices}

Table 1.

The Results of Lesson Observation 1 (Part 1)

\begin{tabular}{lcc}
\hline & $\begin{array}{c}\text { Number of novice teachers who got } \\
\text { yes }\end{array}$ & $\begin{array}{c}\text { Number of novice teachers who got } \\
\text { no }\end{array}$ \\
\hline Opening & 2 & 3 \\
Goal & 5 & 0 \\
Presentation & 3 & 2 \\
Practice & 4 & 1 \\
Performance & 4 & 1 \\
Post Performance & 4 & 1 \\
Lesson wrap-up & 3 & 2 \\
\hline
\end{tabular}

Table 2.

The Results of Lesson Observation 1 (Part 2)

Number of novice teachers who got Number of novice teachers who got no

\begin{tabular}{lcc} 
& yes & \\
\hline Learning environment & 4 & 1 \\
Lesson management & 5 & 0 \\
Corrections & 5 & 0 \\
Student Talk Time & 4 & 1 \\
Group handling & 3 & 2 \\
Professionalism & 5 & 0 \\
Target language & 5 & 0 \\
\hline
\end{tabular}

Table 3.

The Results of Lesson Observation 2 (Part 1)

Number of novice teachers who got yes Number of novice teachers who got

\begin{tabular}{lll} 
& & no \\
\hline Opening & 4 & 1 \\
Goal & 2 & 3 \\
Presentation & 1 & 4 \\
Practice & 5 & 0 \\
Performance & 1 & 4 \\
Post Performance & 2 & 3 \\
Lesson wrap-up & 2 & 3 \\
\hline
\end{tabular}

Table 4.

The Results of Lesson Observation 2 (Part 2)

Number of novice teachers who Number of novice teachers who got no

Learning environment got yes

Lesson management

$\begin{array}{ll}4 & 1 \\ 3 & 2 \\ 4 & 1 \\ 5 & 1 \\ 5 & 0 \\ 4 & 0 \\ 5 & 1 \\ \end{array}$

\begin{tabular}{l}
1 \\
2 \\
1 \\
0 \\
0 \\
1 \\
0 \\
\hline
\end{tabular}


Table 5.

The Results of Lesson Observation 3 (Part 1)

\begin{tabular}{lcc}
\hline & $\begin{array}{c}\text { Number of novice teachers who } \\
\text { got } y e s\end{array}$ & $\begin{array}{c}\text { Number of novice teachers who got no } \\
\text { Opening }\end{array}$ \\
Goal & 5 & 0 \\
Presentation & 5 & 0 \\
Practice & 2 & 3 \\
Performance & 3 & 2 \\
Post Performance & 3 & 2 \\
Lesson wrap-up & 5 & 0 \\
\hline
\end{tabular}

Table 6.

The Results of Lesson Observation 3 (Part 2)

\begin{tabular}{lcc}
\hline & Number of novice teachers who got yes & $\begin{array}{c}\text { Number of novice teachers who } \\
\text { got no }\end{array}$ \\
\hline Learning environment & 2 & 3 \\
Lesson management & 4 & 1 \\
Corrections & 5 & 0 \\
Student Talk Time & 5 & 0 \\
Group handling & 5 & 0 \\
Professionalism & 4 & 1 \\
Target language & 5 & 0 \\
\hline
\end{tabular}

